\title{
Move Analysis on Thesis and Dissertation Abstracts: Contrastive Study
}

\author{
Bestari Kirana Putri ${ }^{1}$, Eri Kurniawan ${ }^{1 *}$, Wawan Gunawan ${ }^{1}$, Arif Husein Lubis ${ }^{2}$ \\ ${ }^{1}$ English Education Department, Indonesia University of Education, Indonesia \\ ${ }^{2}$ Korean Education Department, Indonesia University of Education, Indonesia \\ *Corresponding author. Email: eri_kurniawan@upi.edu
}

\begin{abstract}
Move analysis has been a topic of interest for the past decade. It investigates the rhetorical structure of a text as in the moves and the steps employed in a text, for instance in a research abstract. An abstract is the road map to a research article, it has important functions as a screening device which gives readers brief information on the research's topic, methodology, and findings. A burgeoning amount of study of Move analysis on research abstracts has been carried out widely. However, the discussion on Move analysis on research abstracts based on the rhetorical patterns and authors' educational background is less discussed. To fill this gap, this study aims to disclose differences in authors' thesis abstracts and dissertation abstracts based on their educational backgrounds in terms of the rhetorical organizations and linguistic realizations. This study analysed thesis abstracts and dissertation abstracts from different disciplines in one of the universities in Indonesia. The Five-Move Model by Hyland (2000) was adopted as the basic model for the analysis. Based on The Model adopted, the constituent moves, and steps were analysed and perceived in the classes of the selected abstracts. The results of the analysis were examined subsequently, the main move patterns of each discipline, specific moves and steps, and voice and tense employed in each move. Finally, the results of the analyses and pedagogical implications are presented.
\end{abstract}

Keywords: Abstract, linguistic realizations, move analysis, move pattern, rhetorical patterns

\section{INTRODUCTION}

Research article (hereafter RA) has been a topic of interest for a decade for analysts as it is considered an important genre (Ghasempour, \& Farnia, 2017). RA contains a pair of purpose, as in to outspread new innovations for the discourse community and to influence the discourse community members to acknowledge the statements (Hyland, 2000). One of the ways to outspread the new innovations for the discourse community is through publishing the RA by the scholar (Tamela, 2020; Ghasempour, \& Farnia, 2017). It is known that through particular academic genre's structure, members of certain academic discourse could make a successful communication (Ebadi, Salman, Nguyen, \& Weisi, 2019). RA contains parts as its body namely a title and abstract, introduction, methods, findings, conclusion, and references, and all of this part of RA is worth to investigate as they have their own linguistic features and specific structural pattern that form them (Kanoksilapatham, 2012). Amnuai (2019) state that recent studies have increased on RA's body part, as in the research abstract.

An abstract of a research article has its own function and importance in academic genre (Darabad, 2016). Swales (1990) also state that an abstract is the road map to a research article, it has functions as a screening device which gives readers brief information on the research's topic, methodology, findings, and conclusion. Although it is a part of RA which is a part of an academic genre, abstract is considered a stand-alone genre (Bhatti, Mustafa, \& Azher, 2019). Due to that reason, Bonifacio (2019) state that analysts who studied RA abstract use genre analysis to evaluate the said genre.

The genre analysis employed to study abstracts is Move analysis. Move analysis aids researchers in analyzing the similarities and the patterns of rhetorical move. One of the common analyses framework for a RA abstract is from Hyland (2000) which called Five-Move Analysis. The framework consists of five rhetorical moves, they are: introduction (M1), purpose (M2), method (M3), product (M4), and conclusion (M5). The 
introduction presents the research's context and motives. The Purpose presents the purpose of the research. The Method presents the research methodology, namely on the research design, procedures, participants, data collections, and procedures. The product presents the findings and the discussion of the research. The conclusion presents the interpreted result, implication, limitations and suggestions for future research (Bonifacio, 2019; Tamela, 2020)

The studies of RA abstract employing Hyland's Five Move framework has been carried out widely. For instance, the study conducted by Amnuai (2019) analysed the rhetorical move of RA abstracts based on the authors' different culture and linguistic background, with two different corpora which is international journal and Thai journal. The study also employed Hyland's move analysis. The findings of the study stated that the use of voice and tenses were different from the two corpora, but there still are similarities from the rhetorical moves and linguistics realization. Another study was conducted by Bonifacio (2019) who classified the pattern of rhetorical moves, identify the mandatory and non-mandatory moves, and find out the linguistics features of undergraduate students' abstracts. The findings of this study explicate that the M2-M3-M4-M5 (purposemethod-product-conclusion) pattern received the highest number of occurrences. Purpose (M2), method (M3), and product (M4) are considered as the mandatory moves as these moves appeared in all of the samples. Various linguistic features were also found, but from this study, it can be concluded that the students were unaware of abstract genre writing. Studies on thesis and dissertation abstract is also conducted by several researchers, one of them is by Ebadi, Salman, Nguyen, and Weisi (2019). He analysed rhetorical differences and similarities in thesis abstract and introduction comparatively with the amount of two sets of theses abstracts. Amnuai (2019) is also investigating the similar object, he also focused on the linguistics realization of theses abstracts. The results of the former studies indicate that the students employed the steps of (a) Research hypotheses and (b) Outlining thesis structures in their abstracts, differences and similarities were also found in the rhetorical pattern of the abstracts. While the latter showed that there are differences in the introduction and conclusion moves.

Amnuai (2019) state that the study of theses and dissertation abstracts has been carried out, but not as widely as RA abstracts. Meanwhile, a thesis and dissertation abstract are as important as RA abstracts since they are usually the first part which is reviewed by the examiners (Ren, \& Li, 2011). Therefore, being aware of thesis abstract features is important since it is needed for the communicative purpose of giving brief sight to the study. Due to this reason, this study aims to disclose whether there are differences in authors' thesis abstracts and dissertation abstracts based on their educational backgrounds in terms of the rhetorical organizations and linguistic realizations. Hyland's (2000) Five-Move analysis is used in this study as the framework guide.

\section{METHOD}

\subsection{Research Design}

The design employed for this study is qualitative comparative study since it compares thesis and dissertation abstract. The framework used in this study is from Hyland (2000) Five Move analysis. The framework was chosen because it enables us to differentiate the thesis field of the research and the purpose of the study, according to Ebadi, Salman, Nguyen, and Weisi (2019). Another reason is that the framework allows us to get insight on the rhetorical structure of thesis and dissertation abstracts along with their steps and linguistic features (Darabad, 2016; Ebadi, Salman, Nguyen, \& Weisi, 2019; Ghasempour, \& Farnia, 2017; Tamela, 2020).

\subsection{Data Source}

The study chose a master thesis abstract and a dissertation thesis abstract from a Language Department (T1, D1) and Technological Department (T2, D2) in one of the universities in Indonesia. The data were chosen because of the authors' educational background underlying the abstract construction. Semi-structured interview was also conducted to follow up the findings from the move analysis.

\subsection{Data Analysis}

The data collected were analysed using Hyland (2000) five move analysis frameworks. Before the abstracts were analysed, there are some steps taken such as re-reading the thesis and dissertation abstract, then breaking down the paragraph into sentences. These steps were done to familiarize with the data. After these steps, the sentences were analysed using the framework. The first step of analysing the data was pointing the move as we can see in Table 1. After distinguishing the moves, we also analysed the steps which are carried inside the move patterns, to investigate the pattern of the abstract in detail which can be seen in Table 2 .

Table 1. Hyland (2000) Five-Move Analysis

\begin{tabular}{lll}
\hline \multicolumn{1}{c}{ Move } & \multicolumn{2}{c}{ Function } \\
\hline M1 & Introduction (I) & $\begin{array}{l}\text { Presents the research's context and } \\
\text { motives. }\end{array}$ \\
M2 & $\begin{array}{l}\text { Purpose (P) } \\
\text { Presents the purpose of the research. }\end{array}$ & $\begin{array}{l}\text { Presents the research methodology, } \\
\text { namely on the research design, } \\
\text { procedures, participants, data collections, } \\
\text { and procedures. } \\
\text { Presents the findings and the discussion } \\
\text { of the research. } \\
\text { Presents the interpreted result, } \\
\text { implication, limitations and suggestions } \\
\text { for future research }\end{array}$ \\
M5 & Conclusion (C) & \multicolumn{2}{l}{}
\end{tabular}


Table 2. Hyland (2000) Five-Move Analysis (Steps)

\begin{tabular}{ll} 
Move & \multicolumn{1}{c}{ Steps } \\
M1 & Step 1 - arguing for topic significance \\
& Step 2 -making topic generalization \\
& Step 3 - defining key terms \\
& Step 4 - identifying gap \\
M2 & Purpose \\
M3 & Step 1 - describing participants/ data sources \\
& Step 2 - describing instruments \\
& Step 3 - describing procedure and context \\
M4 & Findings \\
M5 & Step 1 - deducing conclusion \\
& Step 2 - evaluating the significance of the research \\
& Step 3 - stating limitation \\
& Step 4 - presenting recommendation or implication \\
\hline
\end{tabular}

After the sentences of the abstracts were labelled by the move and the steps, the linguistic realizations were also analysed by identifying the voice, tenses, and the verbs used in the abstracts.

\section{FINDINGS AND DISCUSSION}

In this section, the aim of this study to disclose whether there are differences in authors' thesis abstracts and dissertation abstracts based on their educational backgrounds in terms of the rhetorical organizations and linguistic realizations are elaborated. The details of the move analysis result and linguistic realizations were elaborated in the subsection below, and as we can see in Table 3.

\subsection{Move, Step Patterns and Occurrences}

The results in Table 3 showed that there are differences and similarity of the thesis abstract and dissertation abstract in term of rhetorical pattern. For T1 and D1 both started with M2, the purpose of the study. The difference between $\mathrm{T} 1$ and $\mathrm{T} 2$ lies at the M1, where the T1 abstract does not have introduction of the study stated within the abstract. Overall, the pattern of the moves is $\mathrm{P}-\mathrm{M}-\mathrm{Pr}-\mathrm{C}$ for the master thesis which is common, according to Ren, and Li (2011), and P-I-M-Pr$\mathrm{C}$ for the dissertation.

Table 3. Move Patterns and Linguistic Realizations

\begin{tabular}{|c|c|c|c|c|c|}
\hline \multirow[b]{3}{*}{ Move } & \multirow[b]{3}{*}{ Pattern } & \multicolumn{2}{|c|}{ Thesis abstract } & \multicolumn{2}{|c|}{$\begin{array}{l}\text { Dissertation } \\
\text { abstract }\end{array}$} \\
\hline & & $\mathrm{T1}$ & $\mathrm{T} 2$ & D1 & D2 \\
\hline & & $\begin{array}{l}\text { P-M- } \\
\text { Pr-C }\end{array}$ & $\begin{array}{l}\text { I-P-Pr- } \\
\text { C. }\end{array}$ & $\begin{array}{l}\text { P-I-M- } \\
\text { Pr-C }\end{array}$ & $\begin{array}{l}\mathrm{I}-\mathrm{P}- \\
\mathrm{M}(\mathrm{Pr})- \\
\mathrm{Pr}-\mathrm{C}\end{array}$ \\
\hline Occu & M1 & $0 \%$ & $66.7 \%$ & $16.7 \%$ & $9 \%$ \\
\hline rrenc & M2 & $6.25 \%$ & $11.1 \%$ & $8.3 \%$ & $18.2 \%$ \\
\hline \multirow[t]{3}{*}{ e } & M3 & $31.25 \%$ & $0 \%$ & $16.7 \%$ & $27.3 \%$ \\
\hline & M4 & $31.25 \%$ & $11.1 \%$ & $25 \%$ & $27.3 \%$ \\
\hline & M5 & $31.25 \%$ & $11.1 \%$ & $33.3 \%$ & $18.2 \%$ \\
\hline \multirow[t]{2}{*}{ Voice } & Active & $81.3 \%$ & $66.7 \%$ & $75 \%$ & $72.7 \%$ \\
\hline & Passive & $18.7 \%$ & $33.3 \%$ & $25 \%$ & $27.3 \%$ \\
\hline \multirow[t]{2}{*}{ Tense } & Present tense & $31.3 \%$ & $100 \%$ & $33.3 \%$ & $90.9 \%$ \\
\hline & Past tense & $68.8 \%$ & $0 \%$ & $66.7 \%$ & $9.1 \%$ \\
\hline \multirow[t]{3}{*}{ Verb } & Action verb & $50 \%$ & $44.45 \%$ & $58.3 \%$ & $63.6 \%$ \\
\hline & Linking verb & $25 \%$ & $11.1 \%$ & $25 \%$ & $9.1 \%$ \\
\hline & Helping verb & $25 \%$ & $44.45 \%$ & $16.7 \%$ & $27.3 \%$ \\
\hline
\end{tabular}

Table 4. Steps Occurrence

\begin{tabular}{llllll}
\multirow{2}{*}{ Move } & \multirow{2}{*}{ Step } & \multicolumn{2}{c}{ Thesis } & \multicolumn{3}{c}{ Dissertation } \\
\cline { 3 - 5 } \cline { 5 - 6 } & & T1 & T2 & D1 & D2 \\
\hline \multirow{3}{*}{ M1 } & S1 & $0 \%$ & $14.3 . \%$ & $0 \%$ & $0 \%$ \\
& S2 & $0 \%$ & $71.4 \%$ & $0 \%$ & $16.6 \%$ \\
& S3 & $0 \%$ & $0 \%$ & $12.5 \%$ & $0 \%$ \\
& S4 & $0 \%$ & $0 \%$ & $12.5 \%$ & $0 \%$ \\
M3 & S1 & $20 \%$ & $0 \%$ & $12.5 \%$ & $33.3 \%$ \\
& S2 & $10 \%$ & $0 \%$ & $12.5 \%$ & $16.7 \%$ \\
& S3 & $20 \%$ & $0 \%$ & $0 \%$ & $0 \%$ \\
& M5 & $0 \%$ & $0 \%$ & $12.5 \%$ & $16.7 \%$ \\
& S2 & $30 \%$ & $0 \%$ & $12.5 \%$ & $16.7 \%$ \\
& S3 & $0 \%$ & $0 \%$ & $0 \%$ & $0 \%$ \\
\hline
\end{tabular}

The move pattern revealed in this study is similar to the analysis result done by Amnuai (2019). As for the T2 and D2, the abstract started M1, the introduction to the study. The differences are on the M3, in the thesis abstract, there is no M3, while in the dissertation abstract M3 is embedded with M4 with the pattern Method + Findings. Both abstracts also put different highlight for their studies based on the abstracts. In the thesis abstract, the writer tried to highlight the introduction to the study, while in the dissertation abstract, the writer emphasizes more on the methods and the findings based on the same occurrence frequency percentage. Overall, the move pattern from T2 and D2 are I-P-Pr-C and I-P-M(Pr)-C consecutively. The detail of the Steps occurrence employed in the abstracts can be seen in Table 4.

The result of data analyses of T1 and D1 above indicates that both abstracts begin with M2, namely Purpose, in which the author lists the objectives of research writing first before including the introduction or introduction of the research field being carried out. As for the thesis abstract, there is no M1 in the abstract above, the author immediately put M2 on the abstract. For M3, the Step steps listed are in order. The author lists the research participants (S1) after which the instrument and research design are included (S2), then lists the procedures for data collection (S3). For Move-4 or the research results are in accordance with the layout, namely after M3 or the research methodology. Finally, the M5 are placed in order after M4, with the Steps going out of order. In the conclusion section, the author includes an evaluation of the results of the research, or the importance of the research carried out (S2) then writes the research implications and recommendations for further research (S4), which means that the author does not include the main conclusions (Step-1) and states the limitations of research that has been carried out (Step-3) in the Conclusion section.

Meanwhile, the analysis of dissertation abstract results shows that in M1, namely Introduction, there is also a sequence that is passed at the Step stage, namely directly in S3 and S4. For M3, the Step stages listed are not consecutive. The author includes the instrument and research design first (S2), then lists the research participants (S1) afterwards. For M4 or the research 
results are in accordance with the layout, namely after M3 or the research methodology. Finally, the M5 are placed in order after M4, with the Steps going out of order. In the conclusion section, the author includes the main conclusions (in the order of S1) then writes the research implications and recommendations for further research (S4), which means that the author does not include an evaluation of the research results or the importance of the research being carried out (S2) and states limitations of the research that has been carried out $(\mathrm{S} 3)$ in the Conclusion section.

The occurrence percentage from both abstracts indicates that the author put emphasize on the conclusion of the study as it stated the implication of the study conducted. The conclusions considered obligatory as it let the author to validate their findings [26], while the others, as in the introduction, purpose, method, and products were having different emphasize level based on the percentage showed.

Table 4 presents the steps' occurrences in both abstract. In the thesis abstract as there is no M1, so there are no steps included in the abstract. There is also no S1 and S3 from M5 in the abstract. The thesis abstract put the highlight on S2 on M5 since it evaluates the significance of the study. Meanwhile on the dissertation abstract, the moves are complete, so each move contains steps in it, although it is not complete. For instance, on $\mathrm{M} 1$, there are no $\mathrm{S} 1$ and $\mathrm{S} 2$, there is also no S3 on M3 and M5. The author put the highlight on the further research recommendation.

The result of $\mathrm{T} 2$ and $\mathrm{D} 2$ can be described as the following: M1 is the dominant move appeared in the T2 abstract which implies that the writer looks at the importance of introducing the topic discussed to the reader, this is realized by the use of S2 on M1 [27]. In the D2, M1 is functioning as the topic's generalization as the writer is introducing the topic of the study as the only Step employed is $\mathrm{S} 2$ where the writer is highlighting the topic generalization in order to support the $\mathrm{S} 1$ as the topic significance. The second is Move-2 in which the writer put the purpose of the study, both for T2 and D2. As for M3, the difference is that T2 does not have M3, while D2 has M3. In T2, the findings of the study are simply stated by Move-4, while in D2 Move- 3 and Move- 4 have the same occurrence frequency, and there is one embedded move in between Move- 3 and Move- 4 with the pattern of Method + Findings. For Move-3, the Steps appeared were S2 and S1 where the instrument and data sources were explained. After that, the writer explained the result of the study in M4. After that, then the writer stated the conclusion of the study in Move-5, which in T2 is realized by $\mathrm{S} 4$ where the writer is presenting the implication of his/ her study, while in D2 the writer stated his/ her conclusion, with the sequence of deducing the conclusion first with $\mathrm{S} 1$, then evaluation the research significance in $\mathrm{S} 2$.

\subsection{Linguistic Realizations}

Table 3 displayed the result of linguistic realizations contained in T1 abstracts. For the T1 abstract, the author uses more Active Voice, around $81.3 \%$ of all sentences (13 of 16 sentences), while the use of Passive Voice is less than the entire abstract, only $18.7 \%$ of the entire abstract ( 3 of 16 sentences). For the use of tenses in the abstract above, there are 11 sentences of Past Tense (from 16 sentences, around $68.8 \%$ of the use of the tense), the remaining $31.2 \%$ is the Present Tense (5 of 16 sentences).

For the D1 abstract, the author uses more Active Voice around $75 \%$ of the entire abstract ( 9 out of 12 sentences), while the use of Passive Voice is less than the entire sentence, only $25 \%$ of the whole sentence ( 3 of 12 sentences). For the use of tenses in the abstract above, there are 8 sentences of Past Tense (from 12 sentences, around $66.7 \%$ of the use of the Tense), the remaining $33.3 \%$ is the Present Tense (4 of 12 sentences). It can be seen that the Active Voice and Past Tense are predominantly used by the author in writing abstracts, both thesis and dissertation.

Another set of data is also displayed in Table III, which is the use of verbs in the abstracts. The table revealed that action verb is similarly predominantly used in the abstract sentences. The use of linking verb and helping verb are about the same amount of usage, accordingly.

\section{CONCLUSION}

This study compared four research abstracts in academic genre which are two thesis abstracts and two dissertation abstracts. This study revealed that there are differences and similarities in regards of rhetorical structures, move patterns, and the linguistic realizations. Difference in rhetorical structure was found as some of the abstract did not employ the Hyland's (2000) entire move pattern. There are some moves that are considered obligatory and conventional based on the appearance of the move pattern form the abstracts. The patterns appeared from the study are P-M-Pr-C for T1 with the method, product, and conclusion as the obligatory moves, and purpose as the conventional move; and P-I-M-Pr-C for D1 with conclusion and product moves as the obligatory move, and purpose as the conventional move; the patterns for T2 and D2 are I-P-Pr-C and I-P-M(Pr)-C consecutively with the introduction, methods, and product moves as the obligatory move, and purpose and conclusion move as the conventional move. The most preferred use of voice is active voice, although passive voice is also appeared in the abstracts. There are differences when it comes to the tense's choice, past tense is preferred in T1 and D1, while T2 and D2 mainly used present tense. 
The outcome of the present study may add to the existent literary study in the field of academic genre particularly in regard to graduate students seeking graduate degrees. Teachers can use genre-based approach to increase students' knowledge in employing the suitable method for writing an abstract. Familiarizing the students with the structural and linguistic features of an abstracts may aid the students in their academic writing for example, writing their research-based paper, articles, thesis, and dissertation. The students will gradually be more sensitive to the obligatory and conventional move that form an abstract in accordance with their academic writing needs or even international conference.

However, this study only focused on small amount of abstract with only two different scope departments in one of the universities in Indonesia. The study of larger scope and different disciplines is suggested.

\section{ACKNOWLEDGMENTS}

This study was supported by a grant from the Research and Community Service Unit, Indonesia University of Education. The authors would like to express appreciation for all the support provided.

\section{REFERENCES}

Amnuai, W. (2019). Rhetorical move structures and linguistic realizations of abstracts in ICT Research articles and master's theses. MFU Connexion: Journal of Humanities and Social Sciences, 8(1), 157-184.

Bhatti, I. A., Mustafa, S., \& Azher, M. (2019). Genre analysis of research article abstracts in linguistics and literature: A cross disciplinary Study. International Journal of English Linguistics, 9(4).

Bonifacio, R. M. (2019). Genre analysis of research abstracts in central Mindanao University. International Journal of Education, 4(31), 225-236.

Darabad, A. M. (2016). Move analysis of research article abstracts: A cross-disciplinary study. International Journal of Linguistics, 8(2), 125-140.

Ebadi, S., Salman, A. R., Nguyen, T. T. L., \& Weisi, H. (2019). Rhetorical structure variations in abstracts and introductions of applied linguistics master's theses by Iraqi and International students. Iranian Journal of Language Teaching Research, 7(1), 101117.

Ghasempour, B., \& Farnia, M. (2017). Contrastive move analysis: Persian and English research articles abstracts in law discipline. Journal of Teaching
English for Specific and Academic Purposes, 739753.

Hyland, K. (2000) Disciplinary discourses: Social interactions in academic writing, Harlow: Pearson Education.

Kanoksilapatham, B. (2012). Research article structure of research article introductions in three engineering subdisciplines. IEEE Transactions on professional communication, 55(4), 294-309.

Ren, H., \& Li, Y. (2011). A comparison study on the rhetorical moves of abstracts in published research articles and master's foreign-language theses. English Language Teaching, 4(1), 162-166.

Swales, J. (1990). Genre analysis: English in academic and research settings. Cambridge University Press.

Tamela, E. (2020, May). Move Structure Analysis on Research Article Abstracts in National and International SCOPUS Indexed Journals. In International Conference on English Language Teaching (ICONELT 2019) (pp. 12-17). Atlantis Press. 